\title{
The Journal of the American Medical Association.
}

Published under the Auspices of the Board of Trustees

ToL. XLIV.

CHICAGO, ILLINOIS, APRIL 29, 1905.

No. $1 \%$.

\section{Original Articles}

\section{SOME INTERESTING AUTOPSY FINDINGS IN EPILEPTICS.* \\ B. ONUF (ONUFROWICZ), M.D. SONYEA, N. Y.}

[From the Pathological Laboratory of the Craig Colony for Epileptics.]

When I assumed the duties of pathologist to the Craig Colony, a year ago, the task before me of studying the pathology of epilepsy seemed a hard one, promising but little fruit. That such a pessimistic feeling had justification will be seen from the following passage by an author of such repute as Gowers, ${ }^{1}$ and whose name is so intimately associated with the subject of epilepsy:

Of the histologic changes revealed by the microscope, most of those which are not common, apart from symptoms, are apparently of secondary origin, the result and not the cause of the convulsions; and the various changes that have been described and have been supposed to be related to the origin of the disease have probably no connection with it, and do not even deserve enumeration. No greater significance can be ascribed to the induration of the cornua ammonis (pes hippocampi) to which weight has been attached by Meynert. Nor is there at present much likelihood that our knowledge will be more definite. The changes in the nerve elements are probably of that molecular character which is revealed only by altered functions and deludes the most minute research.

With such a basis to start from, the prospect of throwing new light on the pathogenesis of epilepsy along the lines of pathologic anatomy and pathologic histology seemed very small indeed. Nevertheless, an expectant neutral attitude of unprejudiced observation seemed indicated and has brought forth some gratifying results, showing that the field of pathologic anatomic and pathologic histologic research is not altogether exhausted and that quite a little may be learned yet about epilepsy from investigation in this direction.

In a recent paper, Dr. M. Allen Starr ${ }^{2}$ makes the statement that a careful review of many facts offered by recent advances of our knowledge of the nervous affections seems to him to demonstrate the fallacy of the prevailing opinion and to prove conclusively that epilensy is usually, if not always, an organic disease.

Whether and to what extent Dr. Starr's statement is borne out by the facts to be presented below is left to the judgment of the reader. The said facts are the outcome of experiences gained in sixteen autopsy cases of "epilepsy," in thirteen of which the brain was examined.

* Rear in the Section on Nervous and Mental Diseases of the American Medical Association, at the Fifty-fifth Annual Session. June. 1904

1. Gowers: A Mannal of Diseases of the Nerrous System, 2d Edition. Philadelohla. 1898 , page 753 .

2. M. Allen Starr: Is Epllepsy a Functional Disease? Jour. of Ferv, and Men. Dis., vol. xxxl. March, 1904.
It should be said here that it is more appropriate to speak of epilepsies than of epilepsy, since the variety of the forms of this disease, if we so choose to call it, is so great that they ought to be kept apart. Indeed, it is my conviction, expressed in a previous publication, ${ }^{3}$ and supported by such an author as Féré, that we should rather consider epilepsy as a symptom than as a disease, which symptom may accompany pathologic processes of different nature and location.

If we put ourselves on this broad and neutral basis, then the anatomic findings here presented may find their due appreciation and, eventually, classification.

Before proceeding to the enumeration of the autopsy findings, a word should be said regarding the difficulties that assail us in attempting to obtain material for pathohistologic investigations.

In the first place, it is very often difficult to obtain an autopsy. This difficulty has been greatly diminished by the legislative efforts of Dr. William P. Spratling, which, pursued through several years, have finally borne fruit. The result of this effort is the passage of a law allowing, under certain restrictions, autopsies on all indigent cases dying at the colony, and affording thus a greater number of autopsies than it was possible to obtain before it was passed. While the restrictions above mentioned are still quite considerable, the passage of this law is a great step in advance, the breaking of ground for further gains in that direction. However. even under this law the autopsy has sometimes to be made as late as forty-eight hours after death, which would, under ordinary circumstances, entirely spoil the nervous system for histologic investigations. This impossibility of obtaining an early autopsy being of very frequent occurrence, means had to be found of preserving the central nervous system preliminarily as soon as possible after death, so as to make the material available for investigations even under such unpropitious circumstances. This was done by injecting into the dural sac a 12 per cent. solution of formalin by means of lumbar puncture and of puncture through the foramen magnum. This method, which I described in the Medical Record. July 9, 1904, proved very efficient, as shown by the fact that pieces from the cortex of the motor region, cerebellar cortex, caudate nucleus and the medulla of a brain preserved in such manner ${ }^{4}$ reacted beautifully to the neuroglia stain. This, in view of the rapidity with which neuroglia otherwise undergoes postmortem decomposition, shows the value of the method.

The further advantage of the method is that it hardens at the same time and thus preserves the shape of the different structures. It shares this virtue with

3. B. Onuf: Some Features of the Epileptic Attack, Amer. Medicine vol. vii, No. 5, p 183, Jan. 30, 1904.

4. The preliminary subdural formalin injection was made one hour after death, the autopsy 43 hours after death. 
the method of Drs. A. Merer and Dunlap practiced at the Pathological Institute of the New York State Hospitals. namely. hardening of the brain by means of injecting 10 per cent formalin solution into the ascending anta. after tring off the thoracic aorta. While

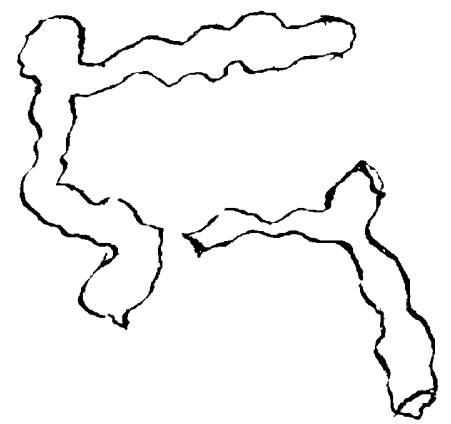

Fig. 1.-Tortuosity and dilatation of capillaries. Drawn from a specimen with camera iucida.

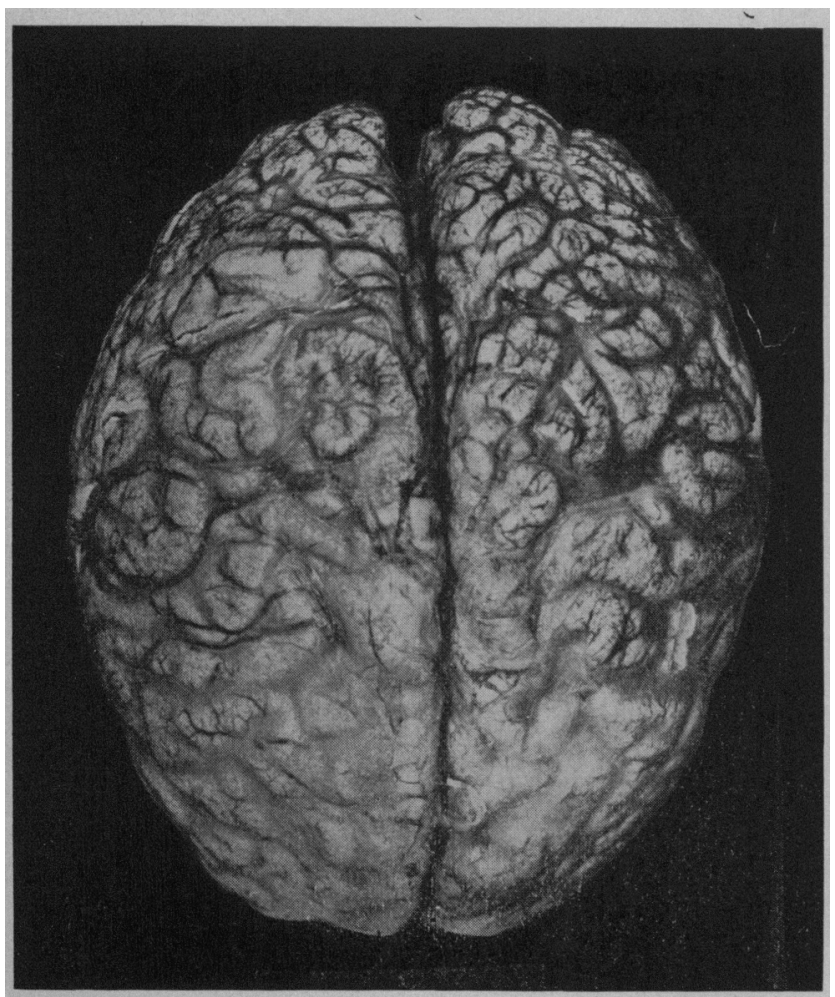

Fig. 2.-Case 13. showing thickening of the nia over the frontoparietal lobes.

this latter method is to be preferred when an carly autopsy can be made and when expense plays no rôle, the subdural injection requires much less formalin and is, therefore, more economical. Moreover, it leaves the body unmutilated.

I proceed now to the enunteration of certain changes found in the deceased epileptics on whom I performed the autopsy. The total number from Junc 1, 1903. until June 1, 1904, amounted to 16.

It is not intended here to enumerate all changes found, but only those which, by their frequency, aroused attention, namely, first, valvular changes of the heart; second, ancurismal dilatation and tortuosity of the capillaries, particularly those of the lungs and of the kidneys; third, acute pneumonia; and fourth, changes in the brain to be specified below.

For clearness sake, the changes found have been tabulated.
TALTCLAR LESIONS.

'The number of cases in which an autopsy of the heart was made was 15 ( since in Case $1 \%$ only a brain autopsy had been permitted). Of these 15 were 12 who showed distinct changes of one valve or the other, or $80 \mathrm{per}$ cent., while in the thirteenth case ( 20 per cent.), they were so slight that we excluded it from consideration.

The valve most frequently affected was the mitral, which, indeed, was involved in every case in which there was a valvular lesion at all; i. e., 12 times out of 15 .

Next in frequency was the disease of the aortic valve: namely, in 5 cases, or 33 per cent., marked involvement, while in 3 cases (Cases 4, 13 and 16) it was of rery slight extent or doubtful.

Less frequent was involvement of the tricuspid, which was distinctly diseased in 3 cases ( 20 per cent.) and slightly, if at all, in the fourth case (Case 13).

By excluding the cases in which the changes were

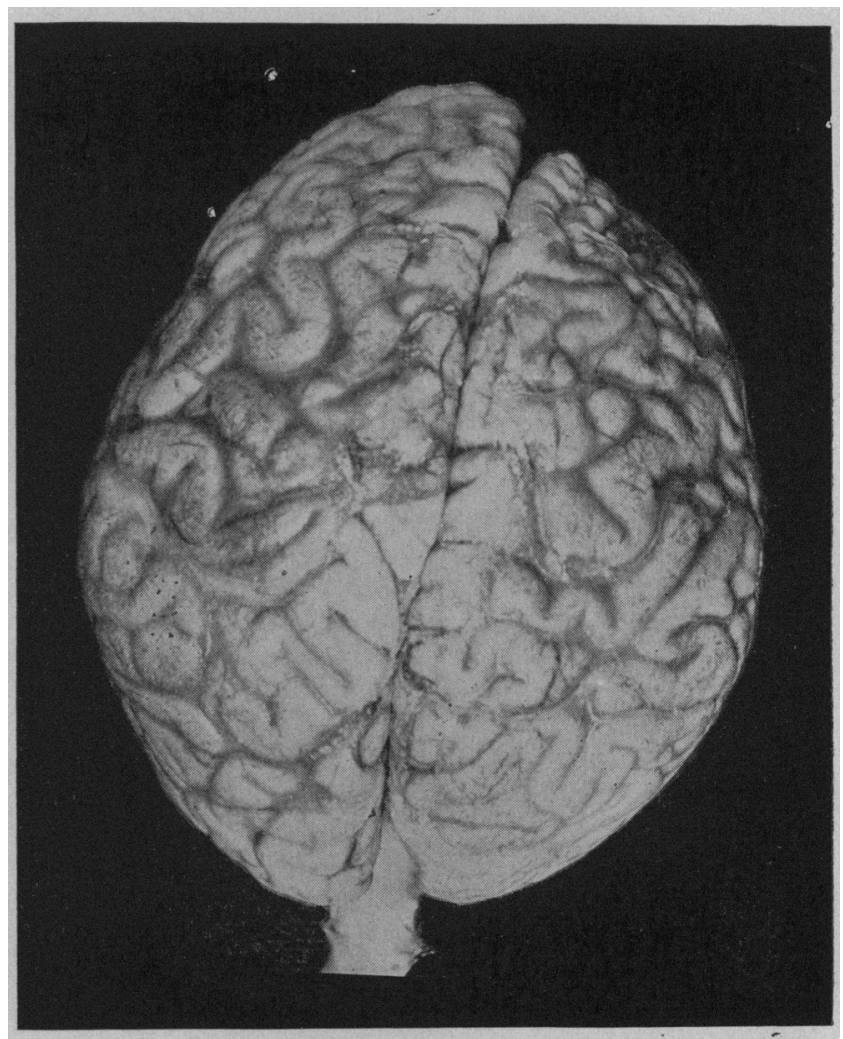

Fig. 3.-Case 12. Circumscribed atrophy of the right frontal lobe.

slight or doubtful, we find the respective valves affected in the following numerical proportions and combinations :

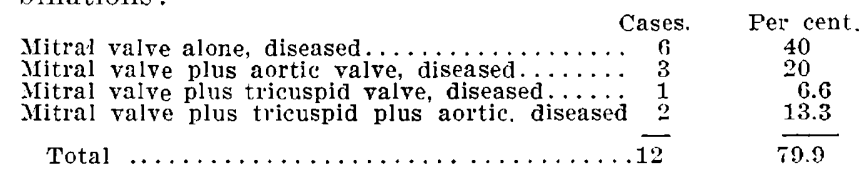

As to the nature of the change, Case 22 ought to first be thrown out as presenting changes of a different character than the rest. In this case the mitral valve showed a wart-like granulation of soft consistency. In all other cases the changes consisted chiefly in a shortening of the valve and a thickening and hardening of its margin. The appearance was most like that of atheroma. No erosions nor calcareous deposits were present on the surface of the valve.

As to the rôle that age might play in the production of these changes, a look at the table shows that only in 
a small percentage senility could be considered the cause, ren if liberal allowance were made in this regard. In C'ase 15 , the age was 94 ; in Case 9 , it was 61 ; in Case 10 , it was 50 ; in Case 6 , it was 42 , and in Case 21 , it was 35 . In these last two cases, senility can really not be considered, and all others were considerably beneath 35 , so that senility can not account for the majority of the cases. Another issue to be discussed was whether the presence of these valvular changes stands in any relationship to the severity and number of attaclis of the rospective patients. For the suggestion of investigating this particular point, I am indebted to a discussion at a conference at Buffalo of the Physicians of the Western state Hospitals of New York, held in May, 1904. Before this conference I read a paper on the same subject. and this suggestion was called forth when $\mathrm{I}$ brought up the question whether the ralvular changes reported werc

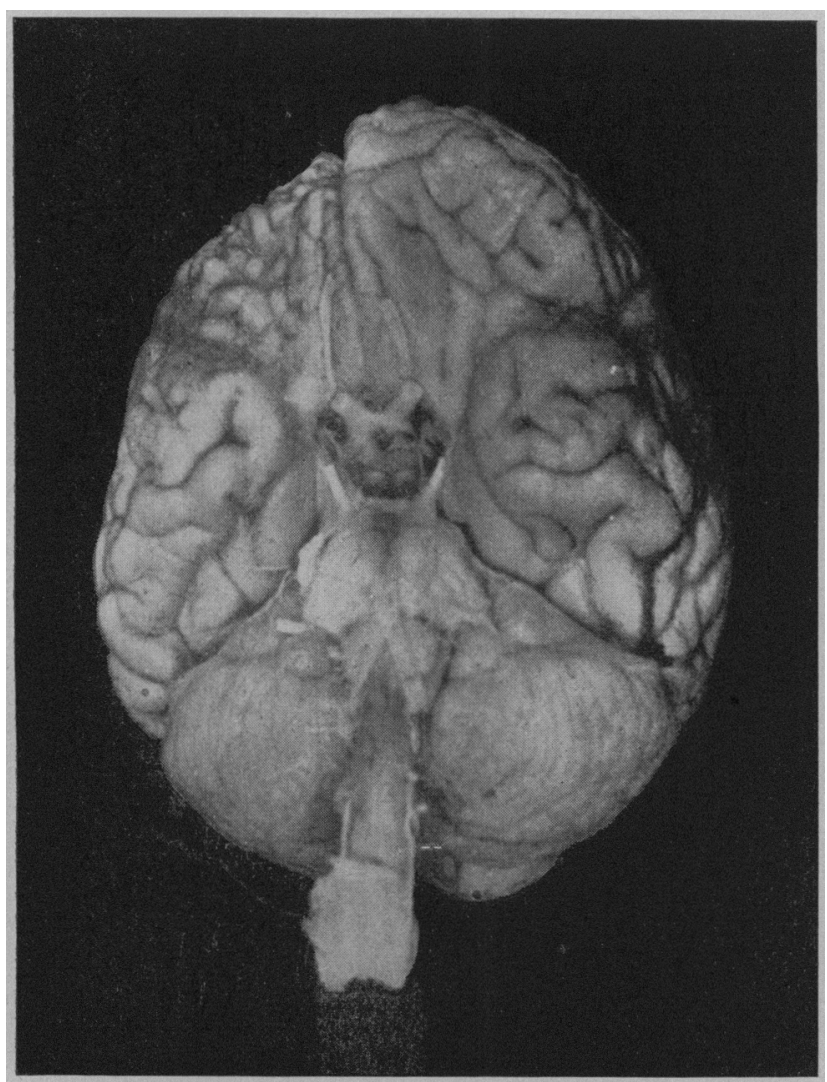

Fig. 4.-Case 12. Circumscribed atrophy of the right frontal lube.

to be considered as primary or as secondary; i. c., proluced by the severe strain accompanying severe seizurcs. In following up this idea, I tried to calculate, so far as joscible, the total number of grand mal and petit mal attacks during the life of each paticnt. That such a alculation can only be approximate is evident. In making it, chief reliance had to be placed on the observations make at the colony, since here each attack, so far as rasible. was recorider. The table crives the result of this attempt, and. on the whole, it does show an unusually laro number of serere attacks; $i$. e. grand mal attacks. In only one case (Case 15) the total number of grand mal attacks was too small to count as an etiologic factor and, in this case, the age of the patient (94. vears) warrants us in considering the changes as senile atheromatous ones. (Case 22, as will be remembered, was excluded, as there the changes were of a totally different character.)
Barring this case, evidence is, therefore, considerably in favor of looking on the valvular changes as secondary and as brought about by the strain to which the circulatory system is put in a grand mal scizure.

Histologic investigations of these valvular changes have not sufficiently advanced to permit a report of the findings.

PA'THOLOGIC CHANGES OF THE CAPILLARIES

In sereral of the autopsy cases, the capillaries of certain organs, particularly of the lungs and kidneys (at least, I have investigated these chiefly) presented striking changes; striking not only by their intensity, but also in their extent, since the majority of the capillaries in these organs were thus involved. The changes consisted in tortuosity of the capillaries and of aneurismal dilation of the same, such as is illustrated in Figure 1.

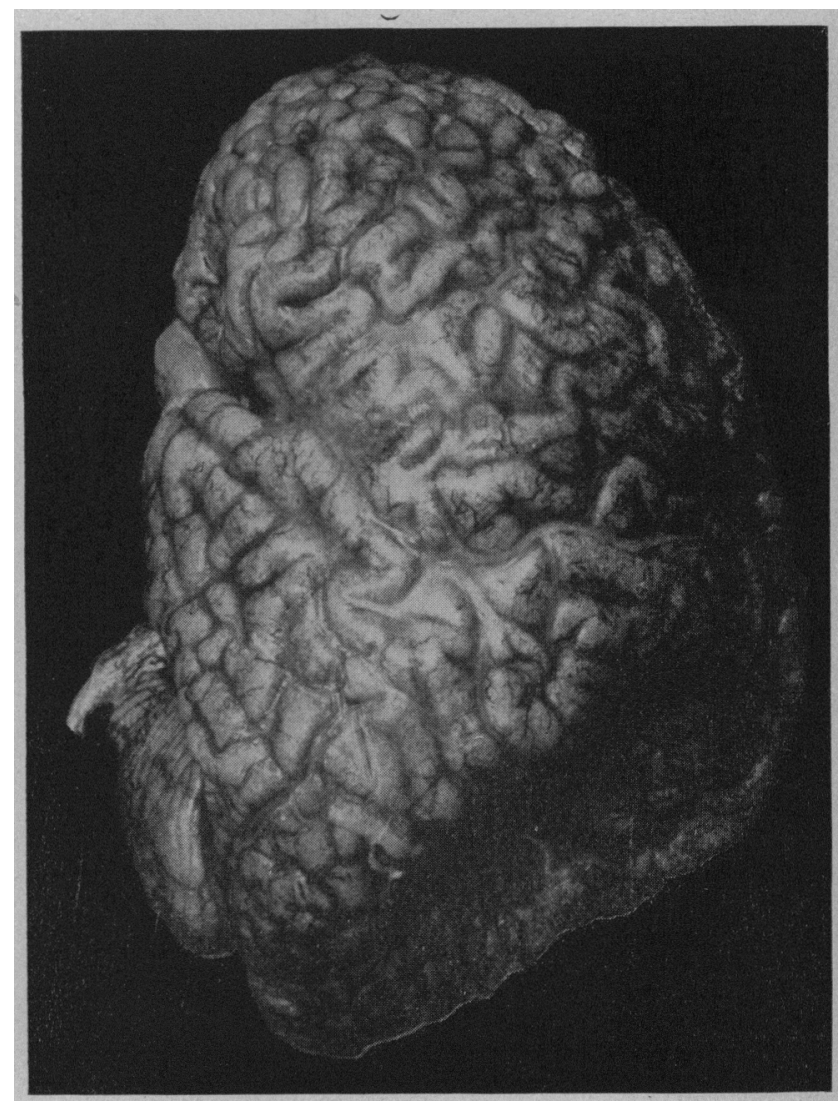

Fig. 5.-Case 17. Hydrocephalus. Left lateral view. Fentricles empty.

In all the cases so far examined in which these capillary alterations were found, valvular changes were also present, and I was first inclined to consider them as sccondary to these. It now seems more probable, however, that they are both due to the same cause; i. e., the tension of the circulatory srstem in severe seizures.

\section{ACUTE PNEUMONIA.}

How frequent a chief or contributory canse of deatl acute pncumonia was, is evident from the table, which show the presence oi this disease in eight of the fourteen autopsy cases in which the lungs were subject to examination; $i . e$. in 58 per cent. One of these ras an aspiration pnemonia: the others were all lobar pnenmonias, with perhaps one exception.

In some of the cases the microscopic diagnosis of pneumonia was supplemented by histologic investigation which confumed it in each case. 
CEREBRAL CHANGES.

Of the sixteen consecutive cases in which I have performed the autopsy, one was unavailable for investigation of the brain, as the brain autopsy was not allowed. In the second it was omitted for some other reason, and in the third the brain was lost. Abstraction of these three leaves thirteen cases in which the brain was examined.

Whenever it seemed desirable, a Meynert section was made; i. e., the pallium was detached from the cerebral axis. $^{5}$ In four cases, however (Cases 12, 14, 17, and 22 ), this was omitted, so as not to spoil the brain for definite lines of investigation.

This leaves nine cases in which the cerebral axis was examined.

On looking over the table, one is struck with the fact that not one case was free from some distinct organic change of the brain itself, exclusive of meninges or blood vessels.

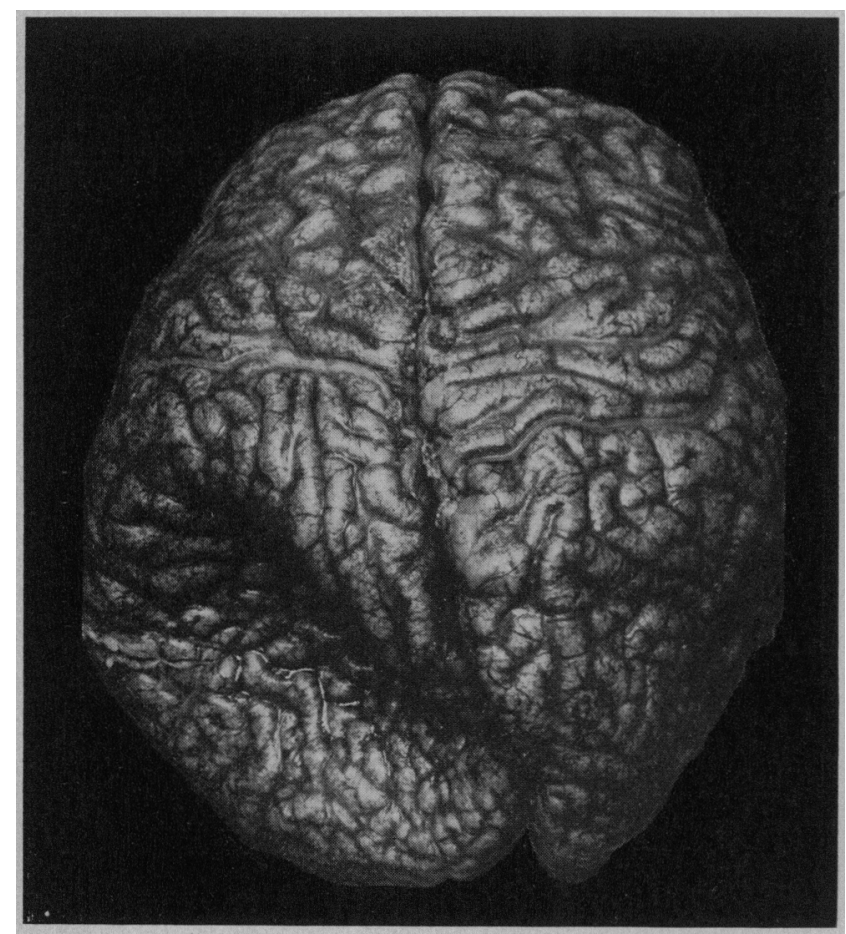

Fig. 6.-Case 17, Upper view. Ventricles empty.

I shall first discuss the lesions of the hemispheres found, then those of the cerebral axis and of the cerebellum.

GROSS LESIONS OF THE CEREBRAL HEMISPHERES.

One feature common to at least ten cases was a very marked thickening of the pia over the hemispheres, chiefly over the convexity of the fronto-parietal lobe. In some of these cases it was, in some regions, as thick as a normal dura. In all of the cases but one (Case 19), there was at the same time a more or less marked shrinkage of the convolutions beneath the thickened pia, affecting on the convexity the frontal lobe, the central convolutions and the upper parietal lobule, sometimes also the lower parietal lobule.

This thickening of the pia is well illustrated in Figure 2 (Case 13).

It is of interest to know that the convolutions of the

5. The cerebral axis consists of the basal ganglia, plus island of Reil, corpora quadrigemina, pons and medulla. base of the brain and those of the occipital and temporal lobes, with the exception of the vicinity of the sylvian fissures, were in most of these cases free from gross atrophic changes.

Gross Vascular Lesions.-Distinct gross vascular lesions affecting the circle of Willis and its branches were present in five cases (Cases $9,14,19,20$, and 22). The arteries in these cases showed tortuosity, irregularities in caliber, and thickening and stiffening of the walls, some features being more marked in one case, and others in another. Beside these diffuse changes, some cases presented marked focal changes, namely:

Circumscribed Atrophy of the Right Frontal Lobe (affecting its entire base and the anterior half of its conrexity).- This was found in one case (Case 12). and is illustrated in Figures 3 and 4 . Unfortunately, the history was inadequate to account for the lesion.

Subdural Hemorrhage Over the Posterior Part of the Second and Third Frontal Convolutions and Lower Part

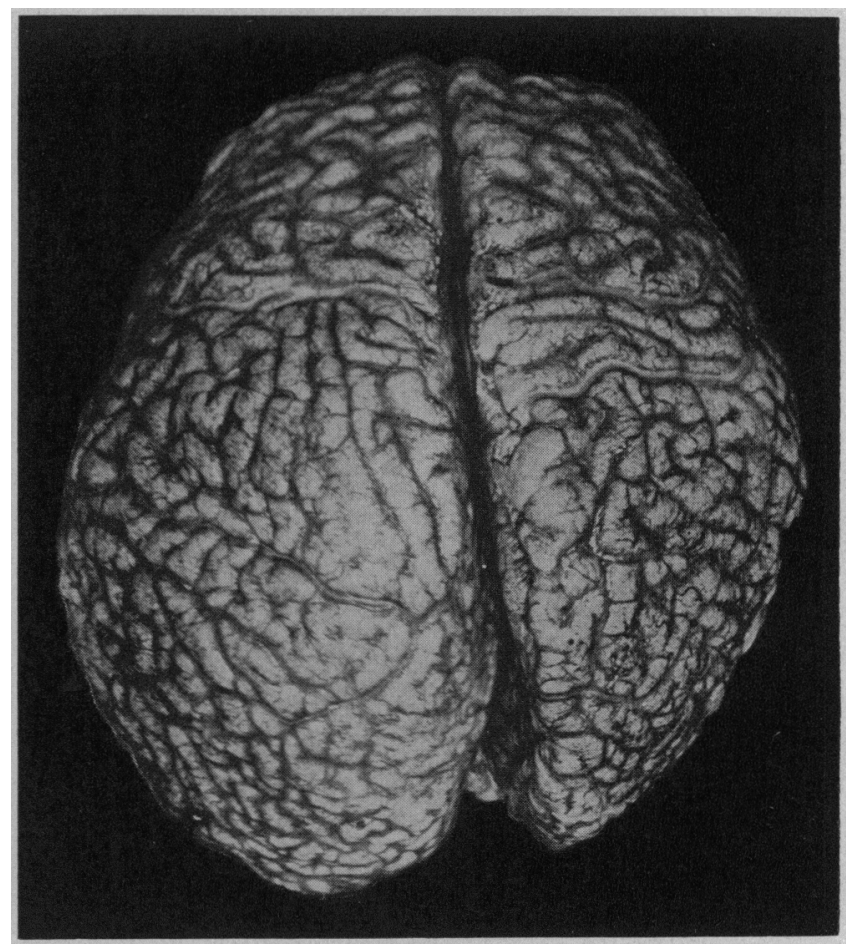

Fig. 7.-Case 17. Upper view. Ventricles filled.

of the Central Convolutions.-In this case, the epileptic seizures were of a Jacksonian character, with preservation of consciousness during the entire attack. Strange enough, however, the muscles involved in the seizures were the arm and neck on the left side, while the lesion was found over the left hemisphere, and none over the right. A few days before death, the patient developed thick speech, marked aphasic disturbance, slight difficulty of swallowing, and some svmptoms pointing to slight laryngeal involvement. The diagnosis was accordingly made of a lesion at the lower end of the central convolutions. This diagnosis was to a great extent confirmed by the autopsy; only, instead of a hemorrhage, a stphilitic lesion, in the nature either of a circumscribed meningitis or a gumma, had been expected, there being the history of a chancre antedating the onset of the epilepsy by about one year.

Internal Hydrocephalus.-This was found in one case. This may be classed among the focal cases, as it affected almost entirely the temporal, parietal and oc- 
cipital lobes, to the complete or almost complete exclusion of the frontal lobe. The left hemisphere was much more affected than the right.

A feature of interest in this case was the smallness and great number of convolutions of the parietal, occipital and temporal lobes, which were of a vermiform type, while those of the frontal lobe were of about normal size and type. This abnormality of gyration suggests a congenital origin of the hydrocephalus. This finds also some confirmation in the history, which says that "labor was prolonged" and the child delivered by forceps. The mother had a severe fright while pregnant. For illustration see Figures 5 to 8, showing the hydrocephalic brain in different aspects, with the ventricles filled and with the ventricles emptied.

GROSS LESIONS OF THE CEREBRAL AXIS AND CEREBELLUM.

Cerebellar Cyst.-The cerebellum showed a marked

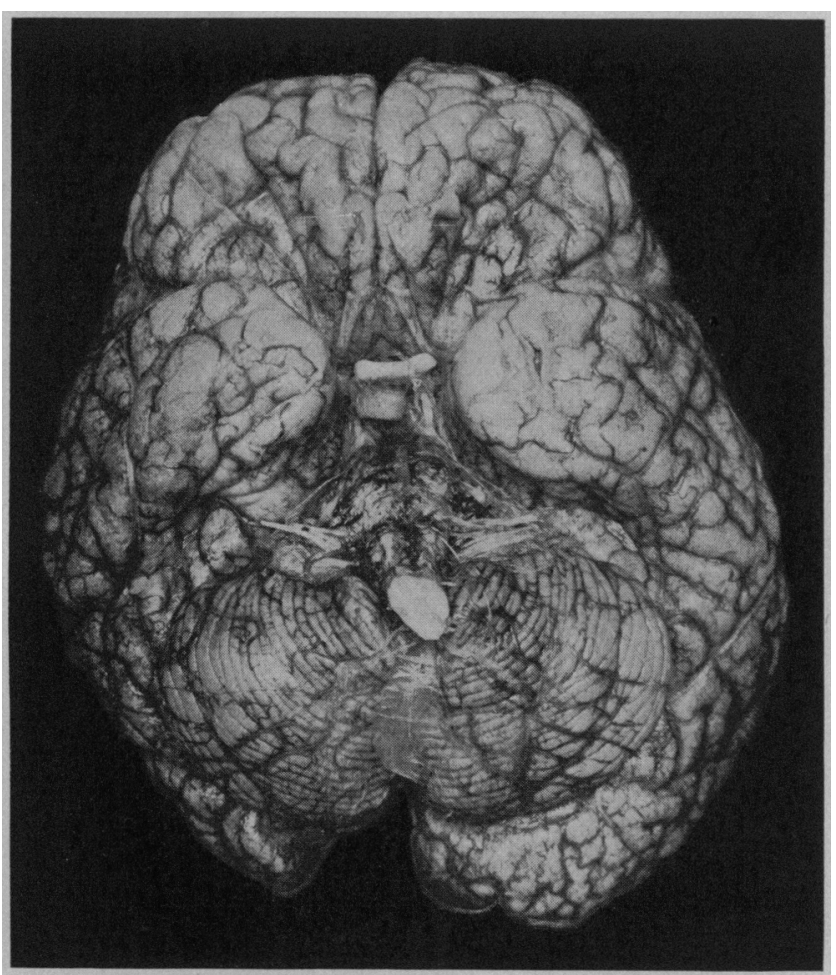

Fig. 8.-Case 17. Basal view. Ventricles filled.

focal lesion in one case, namely, cyst of the upper rermis and of the adjoining part of the cerebellar hemisphere (Case 20). This cyst was about the size of a crabapple and had caused a slight atrophy of the entire cerebellar hemisphere in which it was located. The contralateral olivary body was markedly atrophic.

The cyst was almost directly beneath the surface, being covered mostly by thickened pia. Nothing was left of cerebellar tissue as a covering except a few narrow, thin bridges, passing in transverse directions (Fig. 6. Case 22).

Here the method of preliminary subdural formalin injection proved extremely valuable, as the appearance of the focus would have been greatly changed without it. The autopsy in this case was made 58 hours after death.

Shrinkage of Cerebellar Convolutions.-Another interesting cerebellar change was found in three cases, namely, shrinkage of the convolutions of the upper rermis and of the cortex of the adjacent parts of the cerebellar hemispheres (Case 16, Fig. 10; Case 18, Fig. 14; Case 21, Fig. 17). This was particularly striking in Case 16.

Cerebral Axis.-Here the most interesting changes were found in the thalami and geniculate bodies. The cerebral axis was examined in nine cases, and in seven of these nine cases distinct changes were present in one or both thalami (Figs. 9 to 17 ).

It must be emphasized that the nine cases in which the Meynert section was performed and in which consequently the cerebral axis could be inspected were not picked out from among the rest. The reason why, in the remaining four cases in which the brain autopsy was made, the Meynert section was not performed, was that doing so would have spoiled them for definite lines of investigation.

The changes in the thalamus and geniculate bodies were in the nature of an atrophy. In some cases the surface had a decidedly shriveled appearance-see, for instance, photographs of Cases 6, Fig. 11 (left side) and 21, Fig. 17 (both sides). A difference in the size

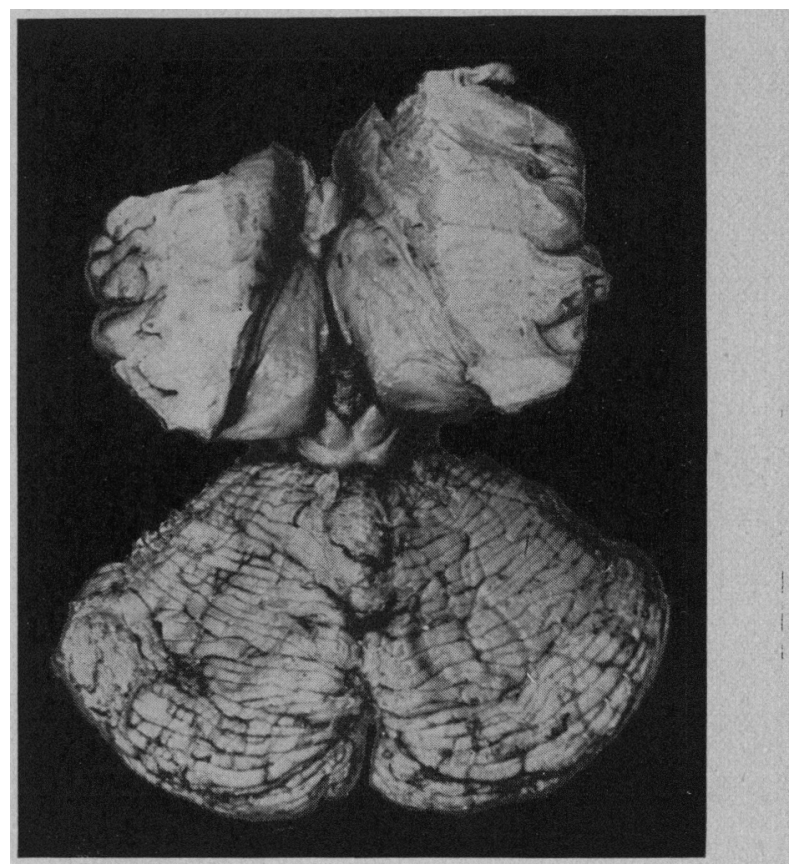

Fig. 9.-Case 9. Left thalamus smaller than right and marked attenuation of pulvinar thalami on both sides.

of the two thalami was noted in Cases 6 (Fig. 11), 9 (Fig. 9), 16 (Fig. 10), and 18 (Fig. 14), in which the left thalamus was smaller than the right one, and in Case 13 (Fig. 13), in which the right thalamus was smaller than the left. Whether in Cases 19 (Fig. 15) and 20 (Fig. 16) the right thalamus was also slightly smaller could not be definitely made out, although it seemed so.

Sometimes the change affected more the pulvinar, sometimes more the other parts of the thalamus.

The pulvinar changes were in some cases extremely marked, the pulvinar being thinned out to a ledge-like wedge instead of forming a well-rounded prominence. This is particularly well illustrated in Cases 9 (Fig. 9) and 13 (Fig. 13) on both sides, and in Case 21 (Fig. 17) on the left side.

The anterior tubercle of the thalamus was likewise extremely reduced in size in some cases (symmetrically or asymmetrically), as a look at the pictures of the nine 
cerebral axes casily shows. In Case 21 (Fig. 17) it was detached to some extent from the remainder of the thalamus, and in Case 20 (Fig. 16) this separation was still more marked, giving the two anterior tubercles an almost pedunculated appearance. It is true that this latter case was the one containing the cerebellar cyst.

The external geniculate body seemed much attenuated and the intermal geniculate body unusually small in a number of cases. However, in this respect $I$ would reserve judgment until further investigation.

The details as to which part was affected in each particular case are also recorded in the table.

A point worthy of note is, further, the disproportion between the size of the corpora quadrigemina on one side and the thalamus on the other. A look at the figures of the different cases shows the differences of the proportion between these two structures. For illustration, two cxtreme cases may be picked out. In Case 18 (Fig. 14), for instance, the mass of the four corpora quadrigemina is almost the size of the left thalamus. In Case 19 (Fig. 15), on the contrary, this mass is only about one-quarter of the size of the left thalamus. The

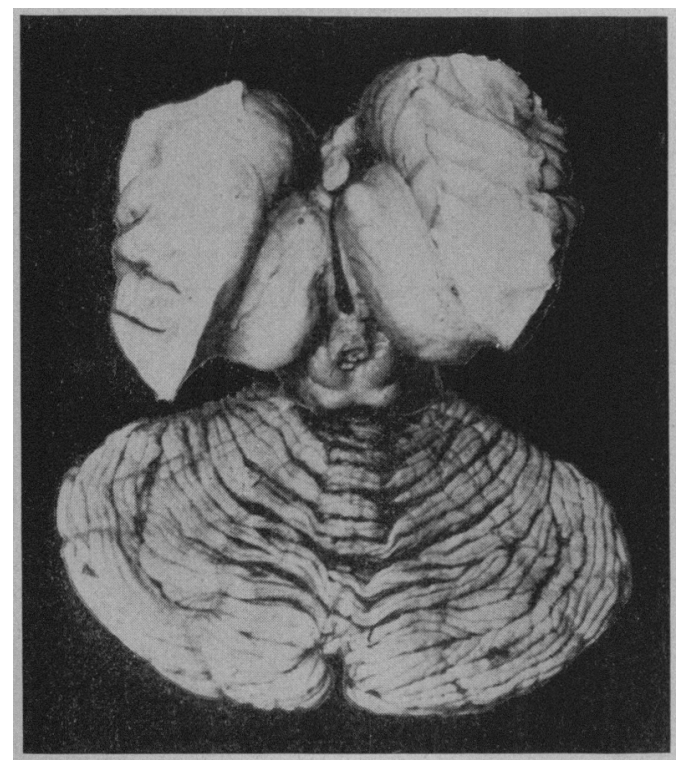

Fig. 10-Case 16. Left thalamus smaller than right. Note also the difference in size of anterior tubercles of the thalamus. Marked shrinkage of convolutions of the superior vermis cerebelli and adjoining parts of the cerebellar bemispheres.

pineal gland here masks the picture somewhat, but leaves, nevertheless, no doubt as to the discrepancy, in this regard, of the two cases mentioned.

It is very probable that in these cases it is the size of the thalami and not that of the corpora quadrigemina that is at fault, nevertheless a reduction in size also of the corpora quadrigemina cannot be quite excluded $a$ priori.

The great frequency and intensity of the changes found in the thalamus and cerebellum call for special discussion of their possible significance, particularly that of the thalamic changes.

EPICRISIS OF THE THALAMIC CHANGES.

A question that first suggests itself in relation to the observed findings in the thalamus is whether such do not represent perfectly normal conditions, $i$. e., whether it is not perfectly common and normal to find such differences in size between the two thalami or between parts thereof, as have been here reported. This question it is safe enough to answer in the negative, since, if such marked asymmetries and proportional differences were common, they could not have escaped observation by many authors and would therefore be well known.

Moreover, the shriveled appearance of the surface of the thalami observed in some cases, as also the wedgelike attenuation of the pulvinar seen in a number of the cases, suggest a process of shrinkage rather than a congenital difference of proportion; $i$.e., an unequal deveiopment. So much can be said previous to histologic investigation.

The changes being acquired ones, the other question to consider is whether they are simply accidental accompaniments, or whether, on the contrary, they have some bearing on the epilepsy, direct or indirect. The conception that they are accidental can hardly be maintained, in view of their great frequency. But, on the other hand, if we assume a relation between these thalamic changes and the epilepsy, three possibilities must again be weighed against each other:

1. The alterations in the thalami might form part of some general process and yet not have anything to do with the causation of the epilepsy itself: To give an illustration: The thalamic pathologic process might

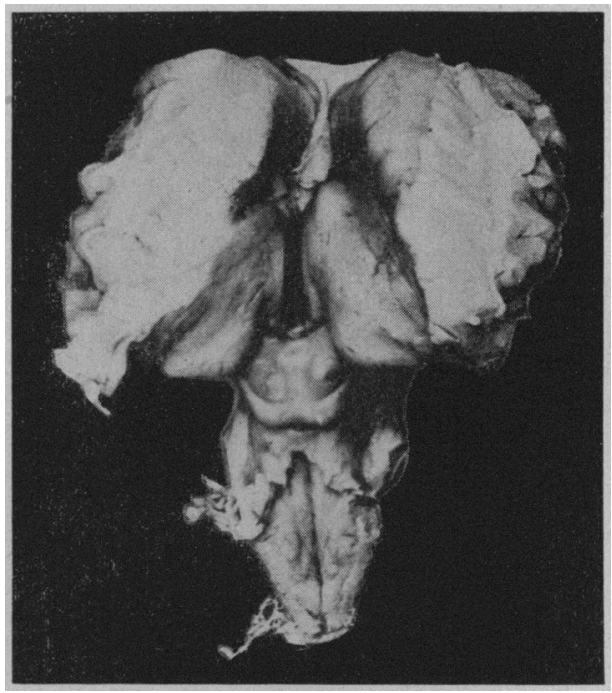

Fig. 11.-Case 6. Also left thalamus smaller than right and difference in size of anterior tubercles of thalamus.

be part of a process affecting the brain in toto; j. e., diffusely; but only that part of this diffuse process involiing the cerebral cortex would have anything to do with the causation of the epilepsy. If this were so, such processes would certainly deserve to be known.

2. The thalamic lesion might be entirely secondary, the result of multiple seizures; whether such result is in the nature of inflammatory processes, or of circulatory. disturbances, or of toxic changes produced by each attack.

3. The third possibility is that of a direct bearing of the pathologic process of the thalami to that of the epilepsy. As we have grown used to consider epilepsy as a cortical disease, the conception that the thalamus may have something to do with it seems like a step backward; i. e., a relinquishment of ground gained; yet the recent advances in our knowledge of the anatomic connections of the thalamus make it appear possible to ascribe to the thalamus some rôle in the provocation of epileptic seizures without denying the instrumentality of the cortex in their production. 
H. H. Hoppe in discussing the anatomic connection and physiology of the thalamus makes the following statement:

It has been established as an anatomic fact, by the researches of Dejerine, Long, Probst, von Monakow, Koelliker, Bechterew, Flechsig, Schïfer and Spiller, that, first, the thalamus is connected by fibers with a large section of the cortex, and reversely that the cortex is connected with the thalamus opticus; and that, second, all the centripetal sensory tracts end in the thalamus.

Hoppe, furthermore, quotes Monakow as having the view that the optic thalamus is an important link in the central apparatus for the perception of impressions made on the special senses and the skin, more especially on the latter.

These facts lend considerable strength to the speculation that an excess of stimulation proceeding from the thalami to the cortex-as might occur in an irritative pathologic process of the thalami-would lead to an overcharge of the elements of the latter, which would

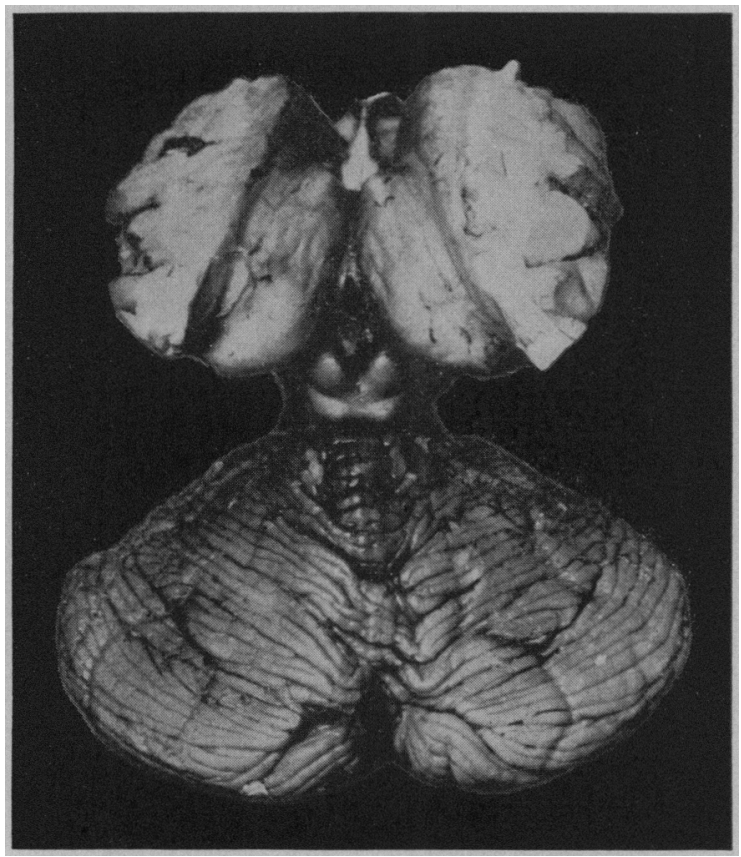

Fig. 12.-Case 5. Thalamus and geniculate bodies apparently free from changes.

from time to time be relieved by an explosive discharge of the accumulated surplus of nerve energy.

While this theory for the present must remain a speculation, it is strengthened by the result of physiologic experiments made by Ziehen. ${ }^{7}$ This author first refers to former experiments, in which he states to have proved that in the dog the clonic part of a convulsion as brought about by faradic cortical excitation was of cortical origin, its tonic part and the running movements, however, of infracortical origin. He then proceeds to a description of his last experiments, the chief results of which concerning us here were as follows:

Superficial mechanical and weak faradic excitation of the thalamus was without effect. Strong faradic excitation owing to coexcitation of the internal capsule causes tonic con-

6. H. H. Hoppe: A Clinical and Pathological Contribution to the Study of the Central Localization of the Sensory Tract, Jour. of Nerv. and Men. Dis., vol. xxxi. May, 1904, p. 281.

7. Ziehen: Zur Physiologie der subcorticalen Ganglien und iiber ihre Beziehungen sum epileptischen Anfall. XIII. Wanderversammlung der südwestdeutschen Neurologen und Irrenïzte Arch. f. Psychiatrie. vol. xx, 1889, p. 584. tractions (of face, forelegs and hindlegs). Severance of the thalamus (by cutting) in the anterior level causes only a momentary startling movement (Zusammenfahren); severance in the posterior levels leads to a mild upheaval ( $A u f$. sturmen) of the animal and an excessive running movement, the latter being occasionally followed, after a short pause, by a tonic convulsion, due, probably, to secondary excitation of further removed parts.

Mechanical or faradic excitation in the domain of the anterior corpora bigemina (as well as the external geniculate body) produces the same morbid running movements, but in markedly exaggerated degree, often accompanied by cries (Schreien). They outlast the excitation by several minutes. Frequently a tonic convulsion follows.

Mechanic and faradic excitation as well as severance (by cutting) in the domain of the posterior corpora bigemina give rise to an extreme tetanic convulsion outlasting the excitation by a long period.

Ziehen concludes from these experiments that in the region of the optic thalami and of the corpora quadrigemina must be situated centers for higher co-ordinated movements. In the above experiments they were prob-

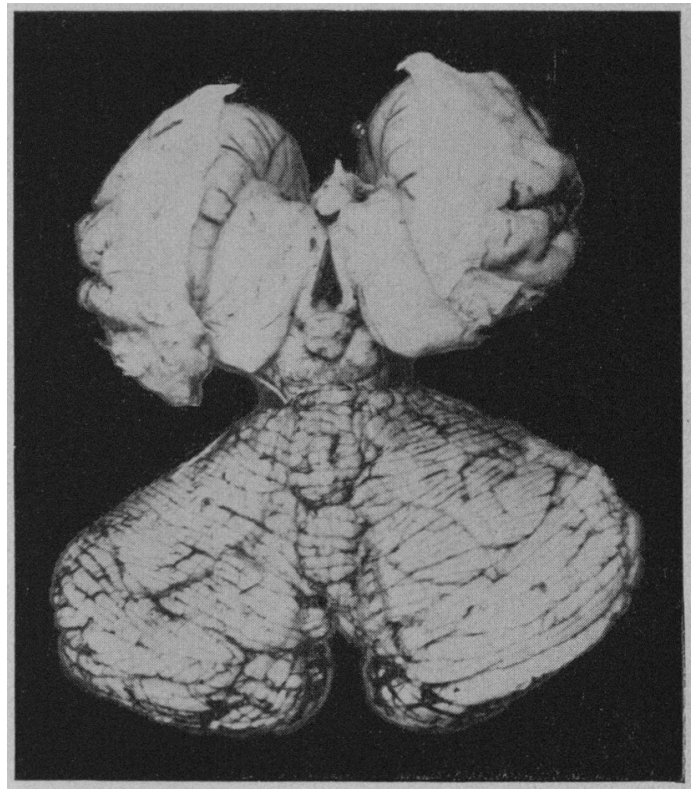

Fig. 13.-Case 13. Right thalamus smaliel than left, and marked attenuation of pulvinar thalami on both sides.

ably not excited directly, but reflexly. He deems it probable that the intracerebral pathway of the optic nerve might play a conspicuous part in this. Also the convulsion produced from the posterior corpora bigemina is probably in the nature of a reflex.

No matter what importance we lend to these experiments of Ziehen-and it seems to me that they deserve some attention-the thalamic changes found in such number in the brains of deceased epileptics at the Craig colony demand an explanation. They show that it is onc-sided to exclusively investigate the cortex or association tracts and no other structures of the brains of cpileptics. It is but fair to admit that the majority of cases forming the basis of this report were advanced ones with marked mental deterioration. Nevertheless, they may also be found in more recent cases; at any rate, such should be investigated in this regard.

Which of the three possibilities of interpreting the thalamic changes will prove to be the correct one, or whether a combination of one with the other will prove 
the right solution, must remain a subject for further research and thought.

It is of some interest to quote here what Dr. Spratlings says relating to Tuke's classification of epilepsies. 'Tuke speaks of "thalamic epilepsy," and defines it as "a form of epilepsy supposed to be due to a lesion in the optic thalamus. Special sense auræ are supposed to oftenest occupy this form."

\section{CLINICAL DEDUCTIONS AND REMARKS.}

Some important clinical deductions are to be drawn from the facts presented in this paper. The changes in the pulvinar and apparently also in the external genicu.

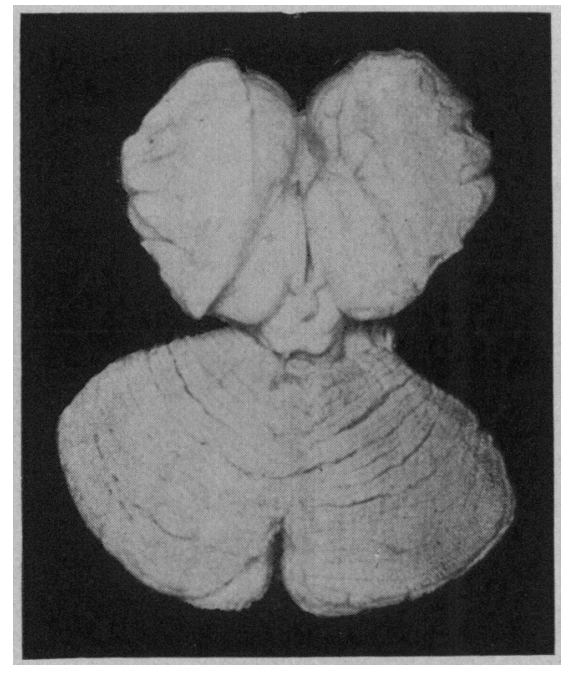

Fig. 14.-Case 18. Left thalamus smaller than right.

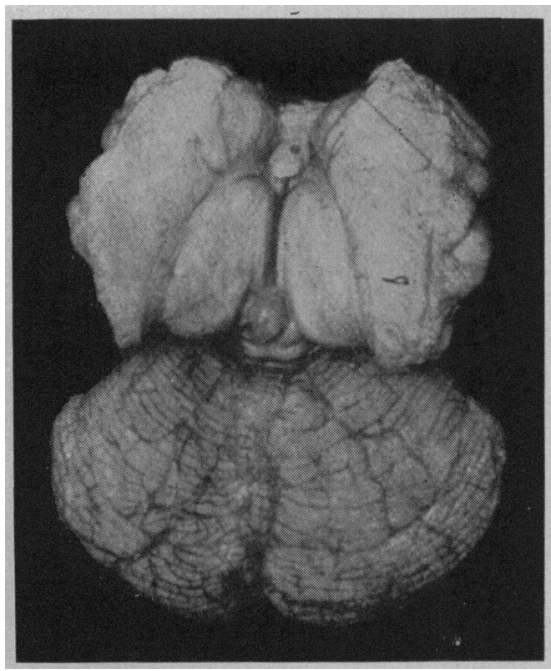

Big. 15.-Case 19. Right thalamus smaller than left.

late body were so marked in some cases that the ophthalmoscope in all probability would have revealed an atrophy of the disc. The importance of examining the fundus in all cases becomes thus evident.

Likewise, the smallness of theinternal geniculate bodies points to an involvement of hearing which also ought to be given clinical consideration. It is to be regretted that in the cases reported by me these points had not been in. quired into clinically. I am responsible only for the

8. Tuke: Dictionary of Psychological Medicine, vol. 1, p. 449, quoted by willam $P$. Spratling in Epllepsy and Its Treatment, Phlladelphia, 1904, p. 26 . anatomic investigation, with the exception of Case 22, which I had the opportunity of examining clinically.

It was first intended to append the clinical histories of the cases, but as these were inadequate, especially in their neurologic aspects, they have been omitted.

It should be said, however, that there was no doubt about all the cases reported being epileptics.

How important a thorough clinical investigation is for the understanding of these cases is shown by the various anatomic findings in those cases $I$ reported, which must have had some clinical equivalents. It is only by a careful comparison of the clinical with the anatomic

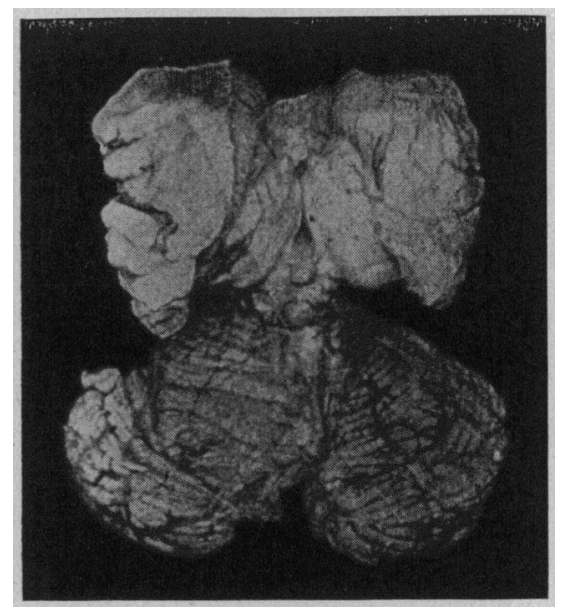

Fig. 16.-Case 20. Cerebellar cyst on left slde; also peculiarly shaped, almost pedunculated anterior tubercles of the thalamus. They are unusually small.

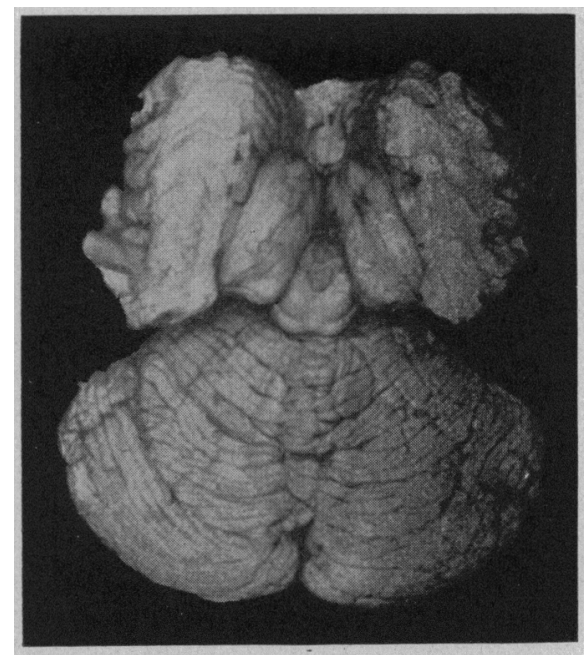

Fig. 17.-Case 21. Right thalamus maller than left. Pulvinar thalami markedly attenuated on left side.

evidence that these cases can attain their full value. Certainly the routine method so much in vogue of simply taking what the German calls an "anamnesis," that is, the family and previous history of epileptics, without making a thorough medical, neurologic and psychic examination of these patients does not do these patients justice, and will not lead to any progress in the understanding of this disease.

The cerebellar changes noted in three cases (shrinkage of the convulsions and adjoining part of the hemispheres in two, cerebellar cyst in one) deserve a brief 
TABLE OF AUTOPSY FINDINGS IN 16 AUTOPSIES OF EPILEPTICS.

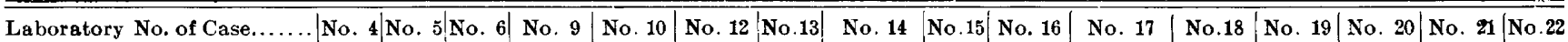

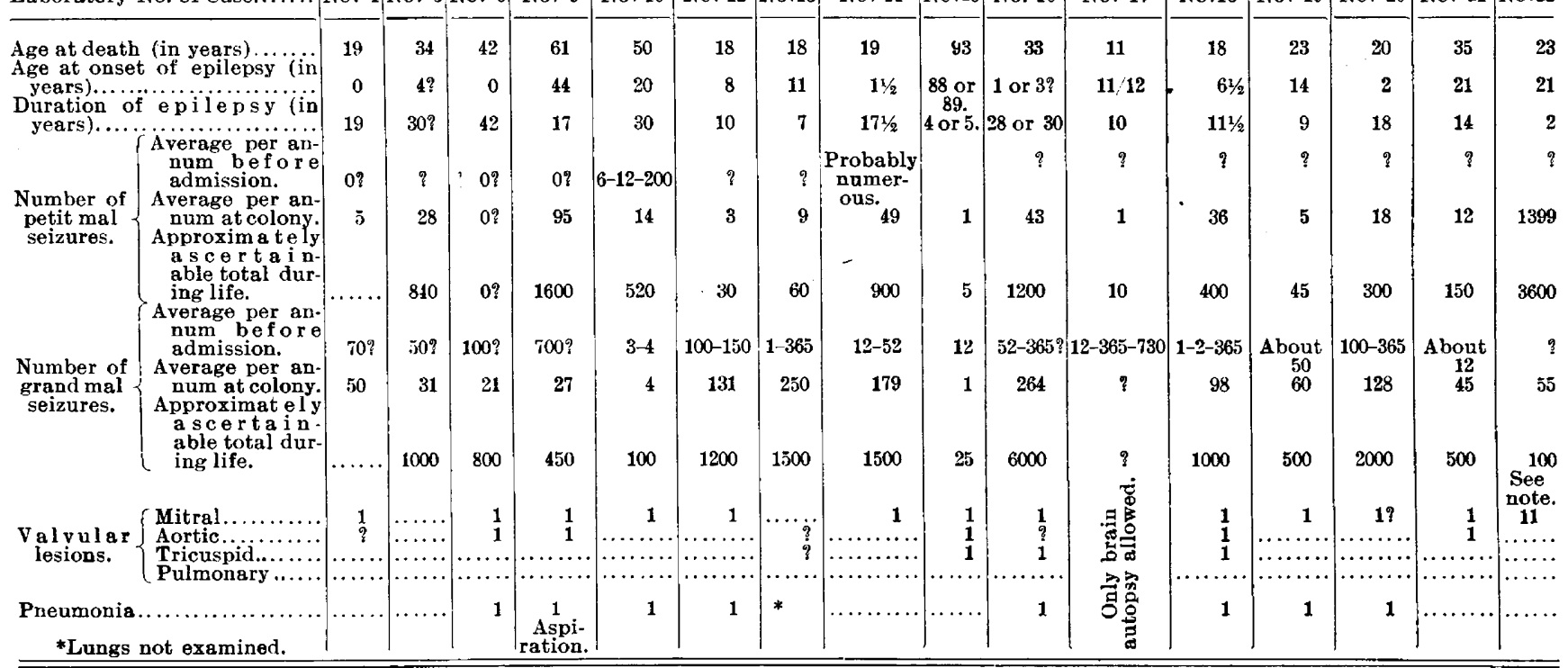

Laboratory No. of Case.............................. 4 No. 5. No. 6 No. 9 No.10 No.12 No.13 No.14 No.15 No.16 No.17 No.18 No.19 No.20 No.21 No.22

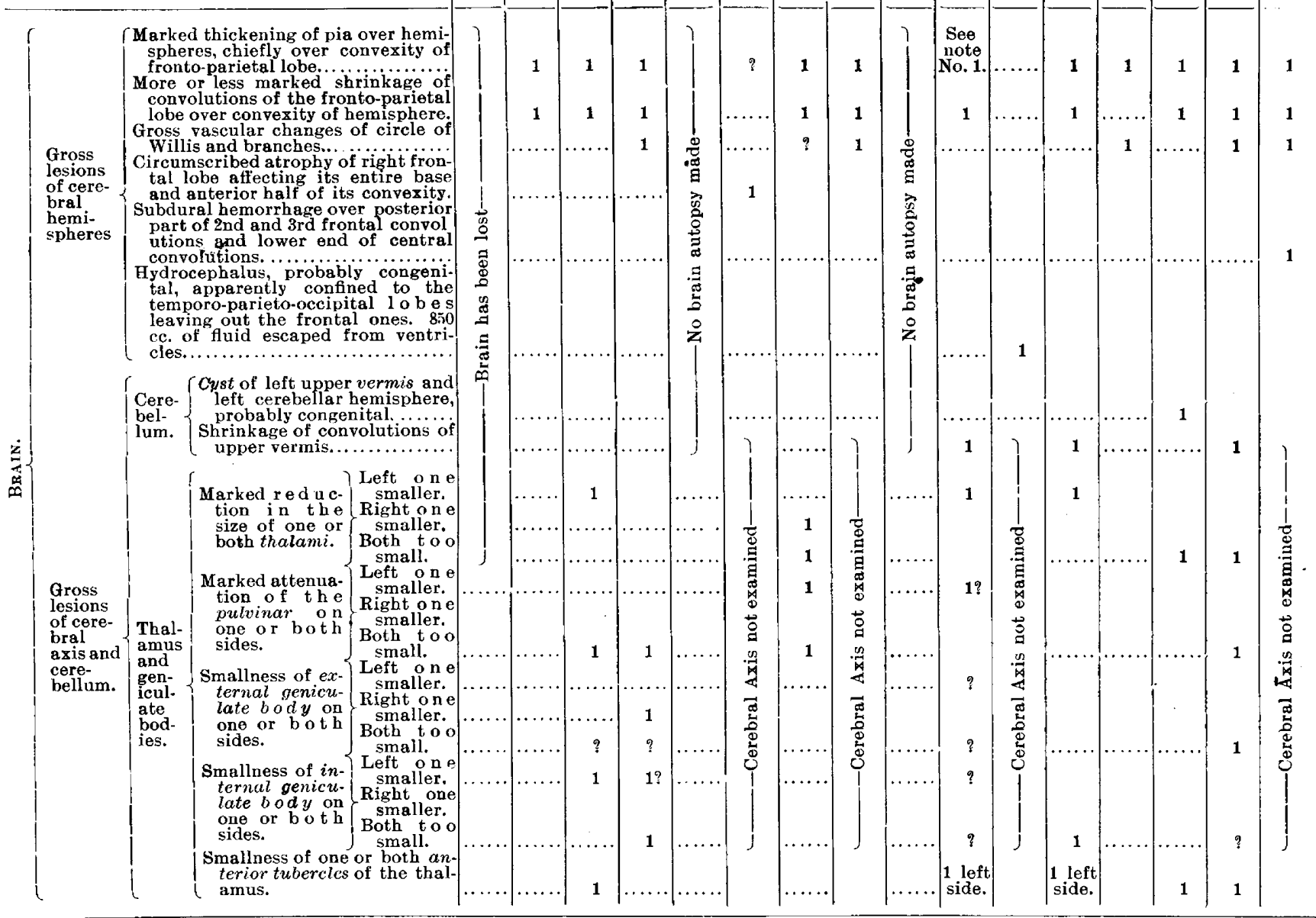

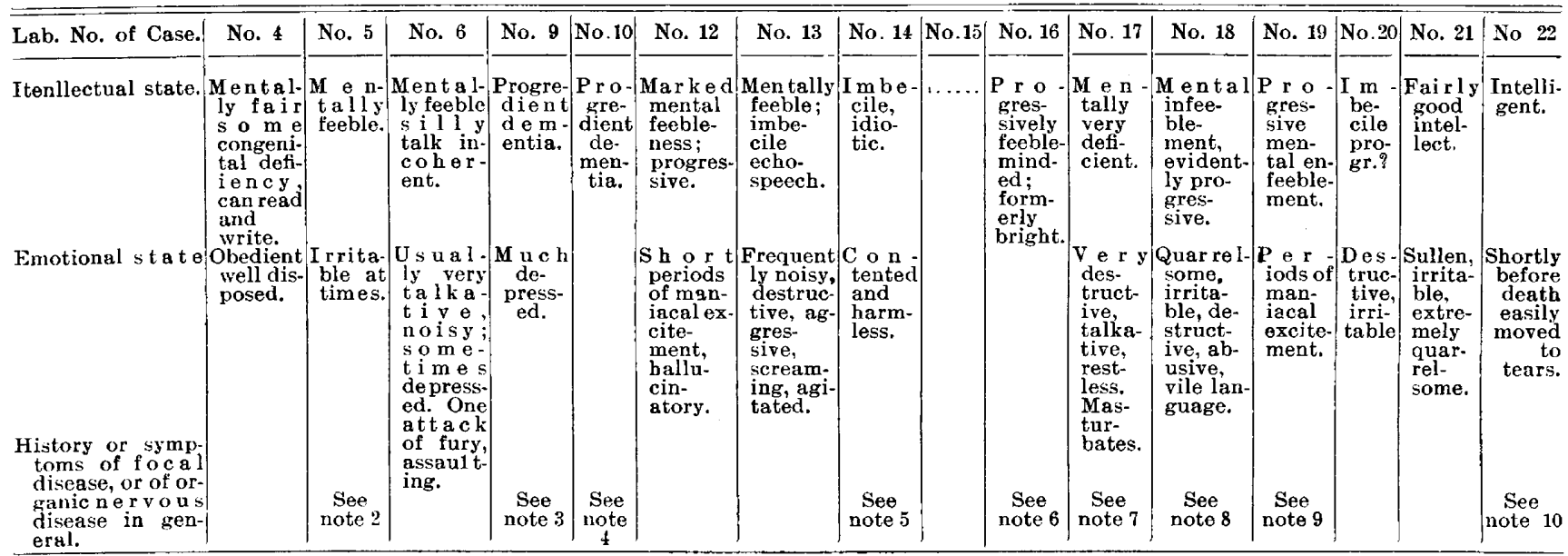


NOTES SUPPLEMENTARY TO TABLE.

Note 1.-Case 16. In this case pia is also thickened, but over different regions and asymmetrically.

Note 2.-Case 5. Exaggeration of deep reflexes on left side.

Note 5 .-Case 9 . Infantile cerebral palsy at six months, i. e. right hemiplegia. Ixamination showed athetoid movements of left (or right?) side, athetoid morements of right hand.

Note 4.. Case 10. Spastio ataxic gait. "Exaggerated reflexes" on both sides. Temporary paraplegia at age of 21 . Syphilitic in fection at age of 25 (or earlier?).

Note 6.-Case 14. Spastic gait. No history notes accounting sor it.

Note 6.-Case 16. Slight right hemiplegia; defective, uncertain, slow speech. "Exaggerated reflexes." I'aralysis came on at age of 3 or $31 / 2$ years, durins an iliness accompanied by high fever and convulsions Attributed to overdose of oplum (?).

Note 7.-Case 17. In this case of bydrocephalus there was dlvergent strabismus, present since admission and for some hours before death a tonlc spasm of right arm and right side of face. Otherwise no reliable date pointing to organic brain lesion.

Note 8.-Case 18. At age of $2 \frac{1}{2}$ stroke of right hemiplegia; at $6 \frac{1}{2}$ years stroke of left hemiplegia. Both recovered (?).

Epilepsy set in after the second stroke. Cinical notes say only :

"Epilepsy set in after the

Note $9 .-$ Case 19 .

ile 10 . Case 22. Weakness of left arm, chlefly after attacks. seizures of Jacksonian type, with preservation of consciousness and involvement almost exclusively of left arm, left side of face and left side of neck. Chancre two years before death. A few days before death he developed thick speech, partial aplasia and paraphasia, disturbance of deglutition and apparent involvement of rocal cords.

Note 11.-Also Case 22. The valvular lesion was here evidently an acute one, possibly a syphilitic one.

discussion. In view of their relative rarity as compared with the thalamic changes, they can not be given as much attention as the latter, but yet should not be allowed to pass without mention.

Claus and Van der Stricht, ${ }^{9}$ who discuss the pathology of epilepsy quite extensively, make the following statements on cerebellar changes in epilepsy.

The sclerotic indurations of the cerebellum are very frequent. They are often found at the autopsies of the epileptics. They have no special significance, they indicate likewise (egulement) a more generalized state of sclerosis. If localized exclusively in the cerebellum they can, just like the sclerosis of the cornea ammonis, of the olivary bodies, or of other parts situated outside of the motor centers, have an etiologic significance in the production of epilepsy.

The authors then go on to quote Duquet as having reported three cases of sclerosis of the cerebellum. They further mention Claus as giving the history of a female epileptic whose gait at the onset simply unsteady (chancelante) became more disturbed in the further course of the disease. The autopsy revealed a sclerous atrophy of the cerebellum. The cells of Purkinje and the nerve cells of the external layer were also diminished and atrophied.

Finally, Claus and Van der Stricht mention Pierret as quoting without comments a case of peripheral atrophy of the cerebellum with accompanying atrophy of the two olivary bodies and integrity of the rhomboid bodies. They conclude by saying: "We find it useless to multiply these instances."

If I have dwelt at some length on the changes of the cerebellum in epileptics it is because some authors have attributed to the cerebellum a relation to emotions. Close contact with epileptics shows, on the other hand, how frequently in these patients the emotions are at fault. (See table, emotional state.) However, I am fully aware that the small material at hand and the speculative character of the emotion theory of the cerebellum does not permit of any definite conclusions.

\section{DISCUSSION.}

Dr. David I. Wolfstein, Cincinnati, declared that this paper is valuable, as it certainly supports in a startling way

9. Claus and Van der Stricht: Essai sur la pathogenie et le traitement de l'epilepsle, Bruxelles, 1895 , p. 165. the recent contribution to the study of these cases made by Dr. Starr, in which he made an effort to pick out a class and place them under the head of organic. It seems that in this group there is confirmatory evidence that organic lesions would be found.

Dr. Wirliam G. Spiller, Philadelphia, stated that he has many brains of epileptics from the Pennsylvania Training School for Feeble-Minded Children, and has observed changes similar to those which have been noted by Dr. Onuf. He does not think it wise to remove the pia, though by so doing better photographs can be made, but one can not then study the condition of the pia. Dr. Onuf's method of hardening the brain has been employed in a somewhat modified form by others. A physician, for the purpose of studying the retina, injected formalin into the eyeball immediately after the death of the patient, and succeeded very well in preserving the nerve cells. Dr. Spiller agreed with Dr. Onuf that it would be well to devote more time to the clinical study of the ocular and aural symptoms.

DR. N. B. ONUF said that in principle Dr. Spiller's objection to removal of the pia is entirely justified. He explained, however, that the removal is not so objectionable as it seems on the surface, since the removed pieces were marked in the relation to the region from which they were taken. The pia was, for instance, removed in a strip over the second frontal convolution, and a note was made which end was the anterior one and which end adjoined the anterior central convolution. In such a manner the pia strips were all marked and removed for future study. Dr. Onuf declared that it is but fair to state that most of these cases were cases of advanced epilepsy with marked mental changes, usually marked dementia, but this does not exclude the possibility of finding such changes also in earlier stages of the disease.

\section{CEREBROSPINAL FEVER.}

\section{EPIDEMIC CEREBROSPINAL MENINGITIS}

\section{J. C. WILSON, M.D.} PHILADELPHIA.

\section{HISTORICAL.}

Two diseases have especially excited the interest and baffled the researches of students of epidemiology and clinical medicine. One is influenza, the other epidemic cerebrospinal meningitis. Influenza has occurred in world pandemics which have been succeeded for varying periods extending over years by recurrent epidemics and sporadic cases and finally by periods of apparent absence of the disease until the sudden recurrence of another great pandemic. The opportunities afforded by the outbreak which began in 1889 have resulted in the discovery of the pathogenic agent of influenza-the bacillus of Pfeiffer-in the recognition of the transmissible nature of the infection and of the existence of sporadic cases by which the disease has been maintained for an indefinite time. But the regions in which the organism has continued to exist and the efficient mechanism by which, after long periods of latency, it suddenly gives rise to its pandemic effects, have thus far eluded research.

Epidemic meningitis-cerebrospinal fever-for about a century has been recognized as a substantive disease. Its occurrence in epidemics more or less extensive and prevailing under conditions wholly at variance with those which obtain with other transmissible or contagious diseases, its terrible symptom-complex, high mortality and the desperate state of many of those whc survive the attack, together with the fact that the disease remains in sporadic form as a continuing menace to the health of communities in which it has once oc- 